\title{
Global warming, elevational ranges and the vulnerability of tropical biota
}

\author{
William F. Laurance a,b,*, D. Carolina Useche ${ }^{\mathrm{b}}$, Luke P. Shoo ${ }^{\mathrm{c}}$, Sebastian K. Herzog ${ }^{\mathrm{d}}$, Michael Kessler ${ }^{\mathrm{e}}$,
} Federico Escobar ${ }^{\mathrm{f}}$, Gunnar Brehm ${ }^{\mathrm{g}}$, Jan C. Axmacher ${ }^{\mathrm{h}}$, I-Ching Chen ${ }^{\mathrm{i}}$, Lucrecia Arellano Gámez ${ }^{\mathrm{f}}$, Peter Hietz ${ }^{\mathrm{j}}$, Konrad Fiedler ${ }^{\mathrm{k}}$, Tomasz Pyrcz ${ }^{1}$, Jan Wolf $^{\mathrm{m}}{ }$, Christopher L. Merkord ${ }^{\mathrm{n}}$, Catherine Cardelus ${ }^{\mathrm{o}}$, Andrew R. Marshall ${ }^{\mathrm{p}, \mathrm{q}}$, Claudine Ah-Peng ${ }^{\mathrm{r}}$, Gregory H. Aplet ${ }^{\mathrm{s}}$, M. del Coro Arizmendi ${ }^{\mathrm{t}}$, William J. Baker ${ }^{\mathrm{u}}$, John Barone $^{\mathrm{v}}$, Carsten A. Brühl ${ }^{\mathrm{w}}$, Rainer W. Bussmann ${ }^{\mathrm{x}}$, Daniele Cicuzza ${ }^{\mathrm{e}}$, Gerald Eilu ${ }^{\mathrm{y}}$, Mario E. Favila ${ }^{\mathrm{f}}$, Andreas Hemp ${ }^{\mathrm{z}}$, Claudia Hemp ${ }^{\mathrm{z}}$, Jürgen Homeier ${ }^{\mathrm{aa}}$, Johanna Hurtado ${ }^{\text {ab }}$, Jill Jankowski ${ }^{\mathrm{ac}}$, Gustavo Kattán ${ }^{\text {ad }}$, Jürgen Kluge ${ }^{\mathrm{e}}$, Thorsten Krömer ${ }^{\text {ae }}$, David C. Lees ${ }^{\text {af }}$, Marcus Lehnert ${ }^{\mathrm{ag}}$, John T. Longino ${ }^{\text {ah }}$, Jon Lovett ${ }^{\mathrm{p}, \mathrm{q}}$, Patrick H. Martin ${ }^{\text {ai }}$, Bruce D. Patterson ${ }^{\text {aj }}$, Richard G. Pearson ${ }^{a}$, Kelvin S.-H. Peh ${ }^{\text {ak }}$, Barbara Richardson ${ }^{\text {al }}$, Michael Richardson ${ }^{\text {al }}$, Michael J. Samways ${ }^{a m}$, Feyera Senbeta ${ }^{\text {an }}$, Thomas B. Smith ${ }^{\text {ao }}$, Timothy M.A. Utteridge ${ }^{\mathrm{u}}$, James E. Watkins ${ }^{\circ}$, Rohan Wilson ${ }^{\text {ap }}$, Stephen E. Williams ${ }^{\mathrm{c}}$, Chris D. Thomas ${ }^{\mathrm{i}}$

a School of Marine and Tropical Biology, James Cook University, Cairns, Queensland, Australia

${ }^{\mathrm{b}}$ Smithsonian Tropical Research Institute, Balboa, Ancón, Panama

${ }^{c}$ Centre for Biodiversity and Climate Change Research, James Cook University, Townsville, Queensland, Australia

${ }^{\mathrm{d}}$ Asociación Armonía, BirdLife International, Santa Cruz de la Sierra, Bolivia

e Institute of Systematic Botany, University of Zürich, Zürich, Switzerland

${ }^{\mathrm{f}}$ Instituto de Ecología, Xalapa, Veracruz, Mexico

${ }^{\mathrm{g}}$ Institut für Spezielle Zoologie und Evolutionsbiologie mit Phyletischem Museum, Jena, Germany

${ }^{\mathrm{h}}$ Department of Geography, University College London, London, UK

${ }^{\mathrm{i}}$ Department of Biology, University of York, York, UK

${ }^{\mathrm{j}}$ Institute of Botany, University of Natural Resources and Applied Life Sciences, Vienna, Austria

${ }^{\mathrm{k}}$ Department of Animal Biodiversity, University of Vienna, Rennweg, Vienna, Austria

${ }^{1}$ Zoological Museum of the Jagiellonian University, Krakow, Poland

${ }^{\mathrm{m}}$ Institute for Biodiversity and Ecosystem Dynamics, Universiteit van Amsterdam, Amsterdam, Netherlands

${ }^{n}$ Division of Biological Sciences, University of Missouri, Columbia, MO, USA

${ }^{\circ}$ Department of Biology, Colgate University, Hamilton, NY, USA

${ }^{\mathrm{P}}$ CIRCLE (Centre for the Integration of Research, Conservation and Learning), Environment Department, University of York, UK

${ }^{\mathrm{q}}$ Flamingo Land Ltd., Malton, UK

${ }^{\mathrm{r}}$ Universite de La Reunion, St. Denis, Reunion

${ }^{s}$ The Wilderness Society, Denver, CO, USA

${ }^{\mathrm{t}}$ Laboratorio de Ecología, Universidad Nacional Autónoma de México, México D.F., Mexico

u Royal Botanic Gardens, Kew, Richmond, Surrey, UK

${ }^{\mathrm{v}}$ Department of Biology, Columbus State University, Columbus, GA, USA

${ }^{\mathrm{w}}$ Institute for Environmental Sciences, University Koblenz-Landau, Landau, Germany

${ }^{x}$ Missouri Botanical Garden, St. Louis, MO, USA

${ }^{\mathrm{y}}$ Faculty of Forestry and Nature Conservation, Makerere University, Kampala, Uganda

${ }^{\mathrm{z}}$ Lehrstuhl Tierökologie II, Bayreuth, Germany

${ }^{\text {aa }}$ Plant Ecology, University of Göttingen, Göttingen, Germany

ab Organización para Estudios Tropicales, Universidad de Costa Rica, San Pedro, Costa Rica

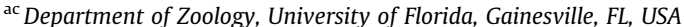

ad Departamento de Ciencias Naturales y Matemáticas, Pontificia Universidad Javeriana, Cali, Colombia

${ }^{a}$ Centro de Investigaciones Tropicales, Universidad Veracruzana, Xalapa, Veracruz, Mexico

af Department of Entomology, Natural History Museum, London, UK

${ }^{\text {ag }}$ Staatliches Museum für Naturkunde Stuttgart, Stuttgart, Germany

${ }^{\text {ah }}$ Evergreen State College, Olympia, WA, USA

ai Department of Horticulture and Landscape Architecture, Colorado State University, Fort Collins, CO, USA

aj Field Museum of Natural History, Chicago, IL, USA

${ }^{\mathrm{ak}}$ School of Geography, University of Leeds, Leeds, UK

al Institute for Tropical Ecosystem Studies, University of Puerto Rico in Río Piedras, San Juan, Puerto Rico

am Department of Conservation Ecology and Entomology, Stellenbosch University, Stellenbosch, South Africa

${ }^{a n}$ Addis Ababa University, Addis Ababa, Ethiopia

${ }^{\text {ao }}$ Center for Tropical Research, University of California, Los Angeles, CA, USA

${ }^{\text {ap }}$ Research School of Biology, Australian National University, Canberra, A.C.T., Australia

\footnotetext{
* Corresponding author at: School of Marine and Tropical Biology, James Cook University, Cairns, Queensland 4870, Australia. Tel.: +61 740421819.

E-mail address: bill.laurance@jcu.edu.au (W.F. Laurance).
} 


\section{A R T I C L E I N F O}

Article history:

Received 9 July 2010

Received in revised form 11 October 2010

Accepted 16 October 2010

Available online 10 November 2010

\section{Keywords:}

Africa

Asia-Pacific

Biodiversity

Climate change

Elevational range

Endemism

Extinction

Global warming

Montane areas

Neotropics

Thermal tolerance

Tropical ecosystems

\begin{abstract}
A B S T R A C T
Tropical species with narrow elevational ranges may be thermally specialized and vulnerable to global warming. Local studies of distributions along elevational gradients reveal small-scale patterns but do not allow generalizations among geographic regions or taxa. We critically assessed data from 249 studies of species elevational distributions in the American, African, and Asia-Pacific tropics. Of these, 150 had sufficient data quality, sampling intensity, elevational range, and freedom from serious habitat disturbance to permit robust across-study comparisons. We found four main patterns: (1) species classified as elevational specialists (upper- or lower-zone specialists) are relatively more frequent in the American than Asia-Pacific tropics, with African tropics being intermediate; (2) elevational specialists are rare on islands, especially oceanic and smaller continental islands, largely due to a paucity of upper-zone specialists; (3) a relatively high proportion of plants and ectothermic vertebrates (amphibians and reptiles) are upper-zone specialists; and (4) relatively few endothermic vertebrates (birds and mammals) are upperzone specialists. Understanding these broad-scale trends will help identify taxa and geographic regions vulnerable to global warming and highlight future research priorities.
\end{abstract}

(c) 2010 Elsevier Ltd. All rights reserved.

\section{Introduction}

Tropical forests are among the biologically richest ecosystems on Earth, but are being rapidly degraded and destroyed by habitat conversion. These forests are also vulnerable to global warming (Williams et al., 2003; Tewksbury et al., 2008; Colwell et al., 2008) and other large-scale environmental changes (Laurance and Peres, 2006), but much uncertainty exists about the nature and magnitude of these anthropogenic impacts on tropical forest organisms.

This uncertainly has three main sources. First, there is considerable variability in the projected rate and magnitude of future changes in climate and atmospheric composition based on computer models. There is much variation, for example, in projected increases of global temperatures and atmospheric $\mathrm{CO}_{2}$ levels by the end of this century (Houghton et al., 2001; IPCC, 2007) and even greater variation in projections of regional and local precipitation (Laurance, 2004; Vera et al., 2006). Changing precipitation could strongly influence the persistence of tropical forests and affect their vulnerability to fire (Hemp and Beck, 2001; Cochrane, 2003).

A second cause of uncertainty is the effect of climate change on tropical ecosystem functioning. For example, a heated debate is being waged between those who argue that undisturbed tropical forests are functioning as a net carbon sink (because forest productivity is increasing in apparent response to rising $\mathrm{CO}_{2}$ levels; Phillips et al., 1998; Laurance et al., 2004; Lewis et al., 2009) versus those who argue that forests are functioning as carbon sources (because higher temperatures could be increasing plant respiration rates and slowing plant growth; Clark et al., 2003; Feeley et al., 2007).

Finally, there is much uncertainty about the effects of rising temperatures on tropical biota. Many tropical species are thought to be thermally specialized, an evolved response to limited temperature variability during the course of the year (Janzen, 1967; Huey, 1976). Species that experience low temperature variation in nature have reduced thermal tolerances (van Berkum, 1988; Addo-Bediako et al., 2000; Ghalambor et al., 2006; Deutsch et al., 2008), including a limited capacity to survive heat waves (Jiguet et al., 2006). One key consequence of this should be a tendency toward elevational specialization in tropical species (Janzen, 1967; Ghalambor et al., 2006; Colwell et al., 2008; McCain, 2009). With strong adiabatic declines in temperature (up to $\sim 0.6{ }^{\circ} \mathrm{C}$ for every 100-m increase in elevation under humid conditions; Still et al., 1999; Raxworthy et al., 2008), many thermally specialized species should have narrow elevational ranges.

Such elevational specialization would account for the striking diversity of restricted-endemic species in cool montane areas of the tropics (Fjeldså and Lovett, 1997; Rahbek, 1997; Ricketts et al., 2005), which are isolated by expanses of warmer lowland habitat. It has been suggested that, if global temperatures rise more than $2-3{ }^{\circ} \mathrm{C}$ in coming decades, high-elevation specialists in the tropics could be among the most imperiled species on Earth (Williams et al., 2003; Hilbert et al., 2004; Ricketts et al., 2005; Thomas et al., 2004; Williams et al., 2007; Raxworthy et al., 2008; Sekercioglu et al., 2008). Rising temperatures could also alter other features of montane areas, such as the height of the cloud base, moisture inputs from cloud-stripping (Pounds et al., 1999; Still et al., 1999), and the diversity and virulence of pathogens (Pounds et al., 2006; Laurance, 2008). The limited data currently available suggest that montane species are increasingly shifting towards higher elevations (Pounds et al., 1999; Raxworthy et al., 2008; Chen et al., 2009).

Lowland species could also be vulnerable to global warming. Many lowland species, particularly ectotherms such as reptiles, amphibians, and invertebrates, appear to have narrow thermal optima and a limited capacity to acclimate to higher temperatures (Huey and Webster, 1976; Hertz, 1979; van Berkum, 1988; Deutsch et al., 2008). Some lowland animal species have high rates of evaporative water loss (Weathers, 1997), which under rising temperatures could increase desiccation stress. An exponential relationship between temperature and metabolic rate in ectotherms means that, for organisms living in warm lowland environments, even modest temperature increases could markedly elevate metabolic rate and energy demands (Dillon et al., 2010). In addition, within vast forest areas such as the Amazon and Congo Basins, lowland species lack clear thermal gradients or nearby upland forests along which they could migrate in response to rising temperatures (Colwell et al., 2008; Wright et al., 2009). Even when montane forests are nearby, the potential dispersal avenues for species into higher elevations are often being disrupted by rapid habitat loss and fragmentation (Peters and Lovejoy, 1994; Pearson and Dawson, 2005). For these reasons lowland tropical species are also vulnerable to global warming-an alarming prospect given their remarkable diversity. 
Although many believe that thermal specialists are quite abundant in the tropics, data on species responses to temperature are limited. Detailed observations of microhabitat selection in Caribbean lizards (Huey and Webster, 1976), experimental analyses of thermal tolerance in rainforest possums (Krockenberger et al., 2004), and physiological studies of tropical insects (Deutsch et al., 2008) and lizards (van Berkum, 1988; Huey et al., 2009) suggest that tropical species often have narrow thermal tolerances and are already living close to their upper thermal limits (Tewksbury et al., 2008; Huey et al., 2009; Dillon et al., 2010). Unfortunately, such studies are time-consuming and expensive, and thus can only be conducted for a tiny fraction of all tropical species. Such limited data make it impossible to develop broad generalizations about the incidence of thermal specialists in the tropics-such as whether they vary among different geographic regions or major functional or taxonomic groups of species.

However, it is possible to infer indirectly the extent of temperature specialization, and hence resilience to thermal change, for entire species assemblages in the tropics. This can be accomplished by evaluating the proportion of any particular functional or taxonomic group-such as flowering plants, beetles, or birds, for instance-confined to a particular elevational zone. Investigators have studied species distributions along tropical elevational gradients for many reasons, such as to evaluate the effects of elevation on species richness and turnover (Terborgh, 1977; Heaney, 2001; Kattan and Franco, 2004), to identify centers of species endemism (Fjeldså and Lovett, 1997; Rahbek, 1997), to test the mid-domain hypothesis (Bachman et al., 2004; McCain, 2004), and to evaluate the extent of thermal specialization (Williams et al., 2009; McCain, 2009) and recent vertical-range shifts (Chen et al., 2009) in montane species.

By critically evaluating raw data from 249 relevant studies, we assess patterns of elevational specialization in terrestrial biota across the tropics. Such analyses do not measure thermal specialization per se, because species confined to a particular elevational zone might be habitat specialists rather than thermal specialists (or, quite possibly, a combination of both). We focus here on three main questions: (1) Does the relative frequency of elevational specialists differ among major tropical regions of the Americas, Africa, and Asia-Pacific? (2) Do patterns of elevational specialization vary between continental and island biotas? (3) Do major functional groups of species (plants, invertebrates, ectothermic vertebrates, and endothermic vertebrates) differ in their patterns of elevational specialization? By helping to identify broad-scale differences in elevational specialization among different taxa and geographic regions, these findings could have important implications for projecting the future impacts of global warming on tropical biota.

\section{Methods}

\subsection{Selection of datasets}

In 2008-2009 we collected 249 published and unpublished datasets on species distributions along elevational gradients in the tropics. Data were collected via a comprehensive literature search and by communicating with $>60$ scientists to acquire additional datasets. To be considered for our study each dataset had to fulfill two criteria: (i) it was conducted in the tropics or subtropics $\left(30^{\circ} \mathrm{N}\right.$ to $30^{\circ} \mathrm{S}$ latitude); and (ii) sampling of species was conducted in a standardized manner at several sites along an elevational gradient.

For each dataset we collected the following information, using published accounts and/or additional data provided by the investigators: (i) a species-by-elevation matrix for all study sites, using presence-absence data for each species; (ii) a synopsis of the sampling methods used; and (iii) descriptions of the study area and any habitat modification at the study sites.

\subsection{Predictor variables}

We tested the effects of three key factors on patterns of elevational specialization. First, each study was classified into one of three broad geographic regions: (1) Africa (including Madagascar and Indian Ocean islands); (2) the Americas (the Neotropics and Caribbean regions); and (3) the Asia-Pacific (South and Southeast Asia, Melanesia, tropical Australia, and tropical Pacific islands).

Second, we categorized each study into those conducted on (1) continents; (2) large ( $>50,000 \mathrm{~km}^{2}$ ) continental islands (Madagascar, New Guinea, Borneo, Sumatra, Java, Sulawesi, major Philippine islands); (3) and oceanic or small continental islands (Hawaii, Hispaniola, Puerto Rico, Comores Islands, Reunion, small Indonesian Islands, all $<50,000 \mathrm{~km}^{2}$ in area).

Finally, we classified the study organisms into four taxonomicfunctional groups: (1) plants (vascular and nonvascular plants as well as lichens); (2) invertebrates (mostly insects such as beetles, ants, moths, orthopterans, and butterflies, but also mollusks and soil macrofauna); (3) ectothermic vertebrates (predominantly salamanders and frogs, with three studies of reptiles); and (4) endothermic vertebrates (birds, bats, and nonflying mammals).

\subsection{Data analysis}

Assessing patterns of elevational specialization in species must be done carefully to avoid potential biases. A direct comparison of the absolute number of elevational specialists among different elevational zones would be confounded by factors such as the total area and primary productivity of available habitat in each zone (Rahbek, 1997; Kattan and Franco, 2004; Williams et al., 2009), both of which generally decline at higher elevations. We avoided this complication by assessing the proportion of elevational specialists within each elevational zone. This largely circumvents concerns about confounding factors, as long as the species assemblage in question was sampled using similar methods and at comparable intensities in each zone.

The 249 datasets differed greatly in their focal taxa, geographic region, sampling design, and range of elevations sampled. A potentially serious bias in such circumstances is 'false absences', in which a species is actually present in an elevational zone but is not detected because it is rare or sampling is inadequate. All studies suffer from some false absences, but the problem becomes a systematic bias if sampling effort varies between elevational zones (because zones with less sampling will have more false absences).

To minimize this problem, we adopted the following approach. First, we divided the sampling sites in each dataset into two equalsized groups (for example, if the investigator sampled 6 sites along a mountainside at 200-m elevational intervals, we divided the samples into two equal groups of 3 each). We defined the 'median elevation' as the midpoint between the two middle-most samples. The sampled elevational range was then divided into an 'upper zone' and 'lower zone', above versus below the median elevation. We then determined the percentage of apparent elevational specialists in each of these two zones. We also combined the two percentages to estimate the overall incidence of 'elevational specialists' in each dataset.

This strategy allowed us to make direct comparisons among different datasets, because the upper and lower zones in each study were unbiased by differential sampling effort. However, some additional precautions were needed. First, although sampling effort was equalized between the upper and lower zones, the elevational range they spanned might not be equal. In fact, the ratio of the wider-to-narrower elevational zone varied markedly among 
the 249 studies, from equality (1:1) to highly skewed (19:1). We arbitrarily rejected any study in which the ratio of the wider-tonarrower zone was greater than 1.5:1, thereby ensuring that the two elevational zones were roughly equivalent in elevational range. This required us to eliminate 44 of the 249 studies.

Second, we also rejected any study in which $<4$ replicate samples were collected along the elevational gradient, or in which the total elevational zone sampled was $<500 \mathrm{~m}$. This eliminated an additional 19 datasets.

Finally, we carefully scrutinized all remaining datasets for overall data quality. We removed any datasets that (i) suffered from substantial habitat disturbance, often at lower elevations, that could potentially alter species distributions; (ii) had inadequate descriptions of the study area; or (iii) used a combination of field and museum data, which made it difficult to standardize sampling effort between zones. This eliminated another 36 datasets.

These precautionary criteria reduced our analysis from 249 to 150 datasets. We used general linear models (GLM), with Systat version 11 , to assess the influence of our three predictor variables (geographic region, island versus mainland, and taxonomic-functional group) on patterns of elevational specialization. To improve normality of our response variables, the proportions of upper zone, lower zone, and all elevational specialists in each dataset were arcsine-square root-transformed prior to analysis (following this, none deviated significantly from normality: $P>0.10$, Wilk-Shapiro tests). As discussed below, data on the median elevation and total elevational range of each study were used as covariates in our analyses. Median elevations were quite evenly distributed but elevational-range data were somewhat right-skewed, and were therefore square root-transformed prior to analysis.

\section{Results}

\subsection{Available datasets}

The 150 datasets included in our final analysis were unequally distributed among the three major tropical regions (Table 1 ). The Americas had by far the largest number of studies (92), followed by the Asia-Pacific (31) and Africa (27). The distribution of studies among taxa was somewhat more even; the largest number focused on plants (56), followed by invertebrates (37), ectothermic vertebrates (32), and endothermic vertebrates (25).

The proportions of the four taxa differed significantly among the three continents $\left(\chi^{2}=13.98, \mathrm{df}=6, P=0.03\right.$; Chi-square test). This difference was mostly the result of a relatively large number of plant datasets, and relative paucity of endothermic-vertebrate datasets, in Africa (Fig. 1). The Asia-Pacific region also had relatively many datasets on endothermic vertebrates, and fewer datasets on ectothermic vertebrates, than did the other continents.

\section{Table 1}

Key features (mean \pm SD) of 150 tropical elevational studies, comparing major tropical regions and continents versus islands.

\begin{tabular}{llll}
\hline $\begin{array}{l}\text { Major tropical } \\
\text { region }\end{array}$ & $\begin{array}{l}\text { Median } \\
\text { elevation }(\mathrm{m})\end{array}$ & $\begin{array}{l}\text { Elevational range } \\
\text { sampled }(\mathrm{m})\end{array}$ & $N$ \\
\hline Americas & $1812 \pm 560$ & $2277 \pm 1007$ & 92 \\
Africa & $1844 \pm 657$ & $2139 \pm 1163$ & 27 \\
Asia-Pacific & $1485 \pm 647$ & $1844 \pm 657$ & 31 \\
Insular status & & & \\
Continents & $1832 \pm 574$ & $2320 \pm 1041$ & 108 \\
Large $\left(>50,000 \mathrm{~km}^{2}\right)$ islands & $1688 \pm 619$ & $1808 \pm 720$ & 31 \\
Small $\left(<50,000 \mathrm{~km}^{2}\right)$ islands & $1114 \pm 560$ & $1312 \pm 605$ & 11 \\
\hline
\end{tabular}

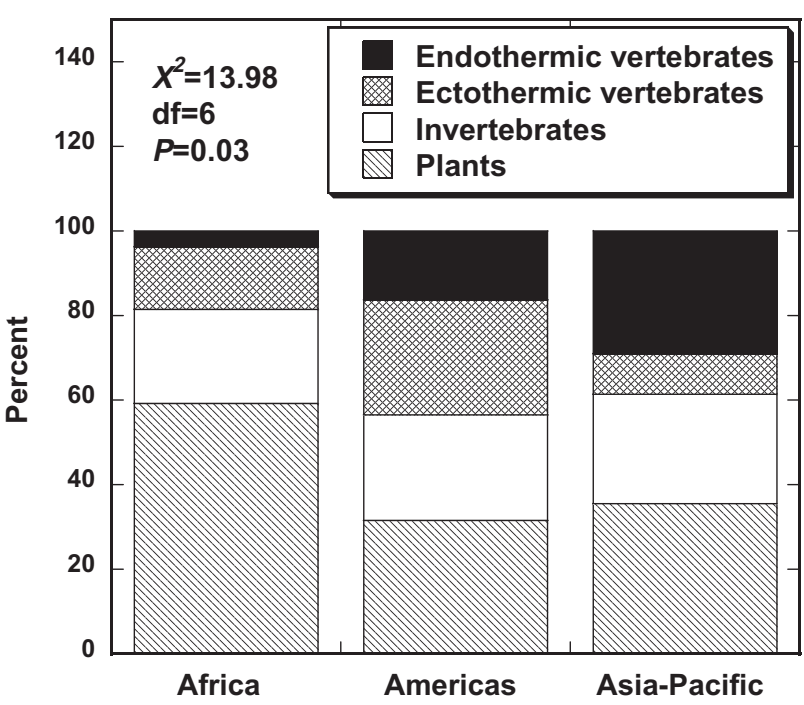

Fig. 1. Percentage breakdown, by taxonomic group and continent, of 150 suitable studies of species distributions along tropical elevational gradients.

\subsection{Artifacts of study design}

As might be expected, studies that sampled a wider elevation range detected a higher percentage of species classified as elevational specialists $\left(F_{1,148}=6.49, R^{2}=4.2 \%, P=0.012\right)$ (Fig. 2$)$. Likewise, studies with a higher median elevation also tended to detect more elevational specialists $\left(F_{1,148}=9.11, R^{2}=5.8 \%\right.$, $P=0.003$; linear regressions).

These patterns were mainly driven by differences among studies in the proportion of species classified as lower-zone specialists. Studies that sampled a wider range of elevations tended to have relatively more lower-zone specialists $\left(F_{1,148}=4.55, R^{2}=3.0 \%\right.$, $P=0.035)$, but no significant difference in the proportion of upper-zone specialists $\left(F_{1,148}=0.10, R^{2}=0.1 \%, P=0.75\right)$. Similarly, studies with a higher median elevation had relatively more lower-zone specialists $\left(F_{1,148}=15.37, R^{2}=9.4 \%, P=0.0001\right)$ but no difference in upper-zone specialists $\left(F_{1,148}=1.27, R^{2}=0.9 \%, P=0.26\right.$; linear regressions).

Another factor that might influence our findings is whether investigators focused on a single mountain (108 studies) or a range

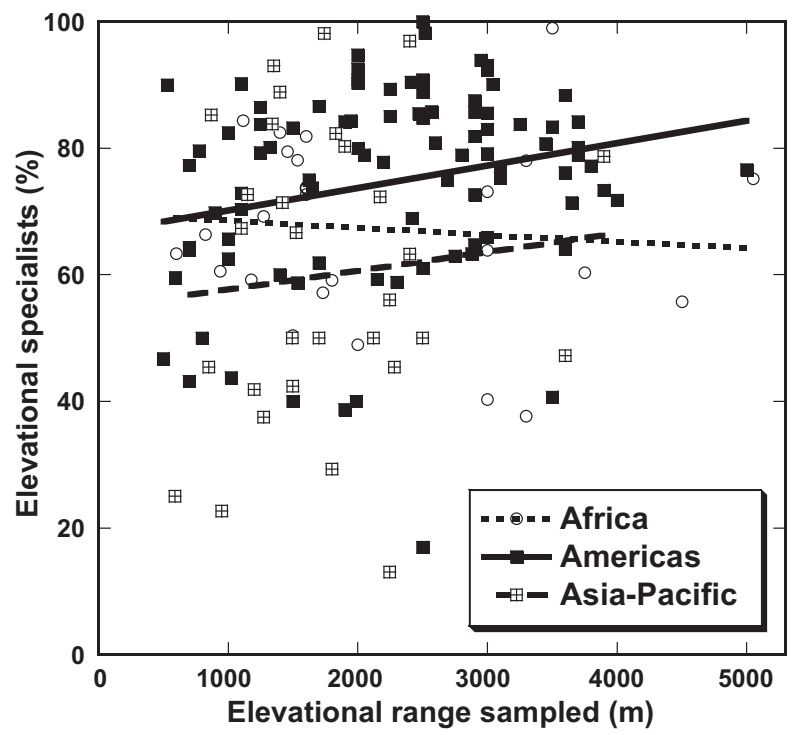

Fig. 2. Percentage of species classified as tropical elevational specialists compared to the range of elevations sampled, for 150 studies on three continents. 
of mountains (42 studies). Because montane areas often have many locally endemic species, whereas lower-zone species are often more broadly distributed, the ratio of upper-zone to lowerzone specialists might be higher when data from multiple nearby mountains are pooled. However, we found no significant difference between studies of single versus multiple mountains in the ratio of upper-zone to lower-zone specialists $(P=0.096$; Mann-Whitney $U$-test). Indeed, this ratio was higher on average in studies of single $(0.79: 1)$ than multiple $(0.60: 1)$ mountains, which is opposite to the trend we anticipated.

Because elevational range and median elevation influenced observed patterns (and were only weakly intercorrelated: $R^{2}=8.6 \%$ ), we included them as covariates in the GLM analyses. We did not distinguish between studies of single versus multiple mountains as this had no significant influence on our findings.

\subsection{Comparisons among major tropical regions}

The GLM analyses revealed several general patterns (Table 2). First, the incidence of elevational specialists differed markedly among major tropical regions (Fig. 3), with the Americas having a significantly higher proportion than did the Asia-Pacific. Africa was intermediate and did not differ significantly $(P>0.1)$ from the other two continents.

Second, there was no significant difference among the major tropical regions in the frequency of lower-zone specialists (Table 2 ), although the proportion of species classified as such was positively influenced by the median elevation of the study. Upper-zone specialists exhibited some tendency to differ among the regions, with a somewhat higher frequency in the Americas than the other two regions, although this difference only approached statistical significance $(P=0.097)$.

Notably, the median elevation of studies (Table 1) in the Asia-Pacific, which had the smallest percentage of elevational specialists, was significantly lower $(P<0.03$; Tukey's test $)$ than that of studies in the Americas and Africa $\left(F_{2,147}=3.89, P=0.023\right)$. AsiaPacific studies also encompassed a significantly $(P<0.03$; Tukey's test) smaller elevational range (Table 1 ) than did those in the Americas and Africa $\left(F_{2,147}=3.26, P=0.04\right.$; one-way ANOVAs). The Americas and Africa did not differ significantly in elevational range.

\subsection{Continents versus islands}

We also found strong differences in the frequencies of elevational specialists among continents ( $n=108$ studies), large islands ( $n=31$ studies), and small islands ( $n=11$ studies) (Table 3 ).
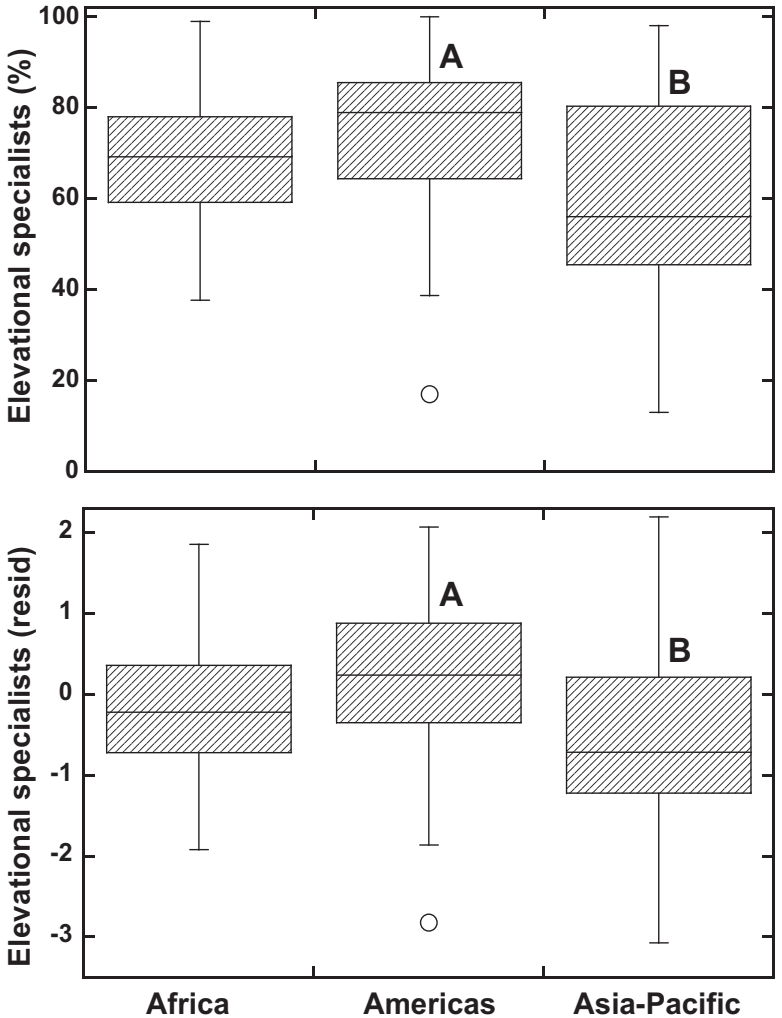

Fig. 3. Box-plot comparisons of the incidence of elevational specialists among three major tropical regions. Comparisons are based on percentage of specialists in each of 150 different studies (above) and the standardized residuals of these percentages once effects of variation in median elevation and elevational range of the study were removed statistically (below). Different letters denote significantly differing regions (regions without letters did not differ significantly from the others).

Continents had a higher proportion of elevational specialists than did large and small islands (Fig. 4). This difference was almost entirely the result of lower frequencies of upper-zone specialists on islands (Fig. 5), as lower-zone specialists differed little in frequency between continents and islands.

As reflected in the range of elevations sampled (Table 1), mountains on islands tended to be lower in elevation than those on continents. We found strong differences in both median elevation $\left(F_{2,147}=7.82, P=0.0006\right)$ and total elevational range $\left(F_{2,147}=7.85\right.$, $P=0.0006$ ) between islands and continents (one-way ANOVAs). On average, the median elevation was higher on continents $(P<0.0001)$ and large islands $(P<0.02)$ than on small islands,

Table 2

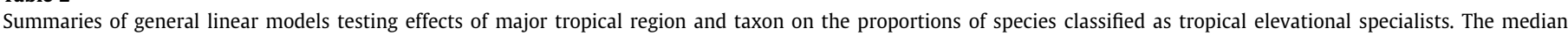
elevation and elevational range of each study were used as covariates to help adjust for differences among studies.

\begin{tabular}{|c|c|c|c|c|}
\hline Factor & d.f. & $F$ & $P$ & Tukey's tests \\
\hline \multicolumn{5}{|c|}{ All elevational specialists (variance explained $=18.9 \%$ ) } \\
\hline Tropical region & 2 & 6.20 & 0.003 & \multirow[t]{4}{*}{ Americas $>$ Asia-Pacific $(P=0.003)$} \\
\hline Taxon & 3 & 0.96 & 0.41 & \\
\hline Median elevation & 1 & 5.42 & 0.021 & \\
\hline Elevational range & 1 & 0.82 & 0.37 & \\
\hline \multicolumn{5}{|c|}{ Lowland specialists (variance explained $=13.4 \%$ ) } \\
\hline Tropical region & 2 & 0.95 & 0.39 & \multirow{4}{*}{ (slope positive) } \\
\hline Taxon & 3 & 1.27 & 0.29 & \\
\hline Median elevation & 1 & 10.50 & 0.001 & \\
\hline Elevational range & 1 & 1.95 & 0.17 & \\
\hline \multicolumn{5}{|c|}{ Highland specialists (variance explained $=12.9 \%$ ) } \\
\hline Tropical region & 2 & 2.38 & 0.097 & \multirow{4}{*}{$\begin{array}{l}\text { Ectothermic vertebrates }(P=0.008) \text { and plants } \\
(P=0.013)>\text { endothermic vertebrates }\end{array}$} \\
\hline Taxon & 3 & 4.82 & 0.003 & \\
\hline Median elevation & 1 & 2.89 & 0.091 & \\
\hline Elevational range & 1 & 0.73 & 0.39 & \\
\hline
\end{tabular}


Table 3

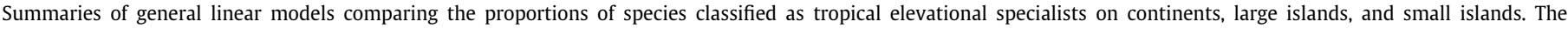
elevational range, median elevation, and taxon of each study were included as covariables to help adjust for differences among studies.

\begin{tabular}{|c|c|c|c|c|}
\hline Factor & d.f. & $F$ & $P$ & Tukey's tests \\
\hline \multicolumn{5}{|c|}{ All elevational specialists (variance explained $=17.6 \%$ ) } \\
\hline Continents versus islands & 2 & 5.06 & 0.008 & Continents $>$ small islands $(P=0.027)$ and large islands $(P=0.057)$ \\
\hline Elevational range & 1 & 0.27 & 0.61 & \\
\hline Median elevation & 1 & 4.15 & 0.044 & (slope positive) \\
\hline Taxon & 3 & 0.99 & 0.40 & \\
\hline \multicolumn{5}{|c|}{ Lowland specialists (variance explained $=12.3 \%$ ) } \\
\hline Continents versus islands & 2 & 0.02 & 0.99 & \\
\hline Elevational range & 1 & 2.26 & 0.14 & \\
\hline Median elevation & 1 & 11.09 & 0.001 & (slope positive) \\
\hline Taxon & 3 & 1.07 & 0.36 & \\
\hline \multicolumn{5}{|c|}{ Highland specialists (variance explained = 17.2\%) } \\
\hline Continents versus islands & 2 & 6.24 & 0.003 & Continents $>$ small islands $(P=0.01)$ and large islands $(P=0.035)$ \\
\hline Elevational range & 1 & 2.22 & 0.14 & \\
\hline Median elevation & 1 & 5.11 & 0.025 & (slope negative) \\
\hline Taxon & 3 & 4.83 & 0.003 & Ectothermic vertebrates $(P=0.015)$ and plants $(P=0.017)>$ endothermic vertebrates \\
\hline
\end{tabular}
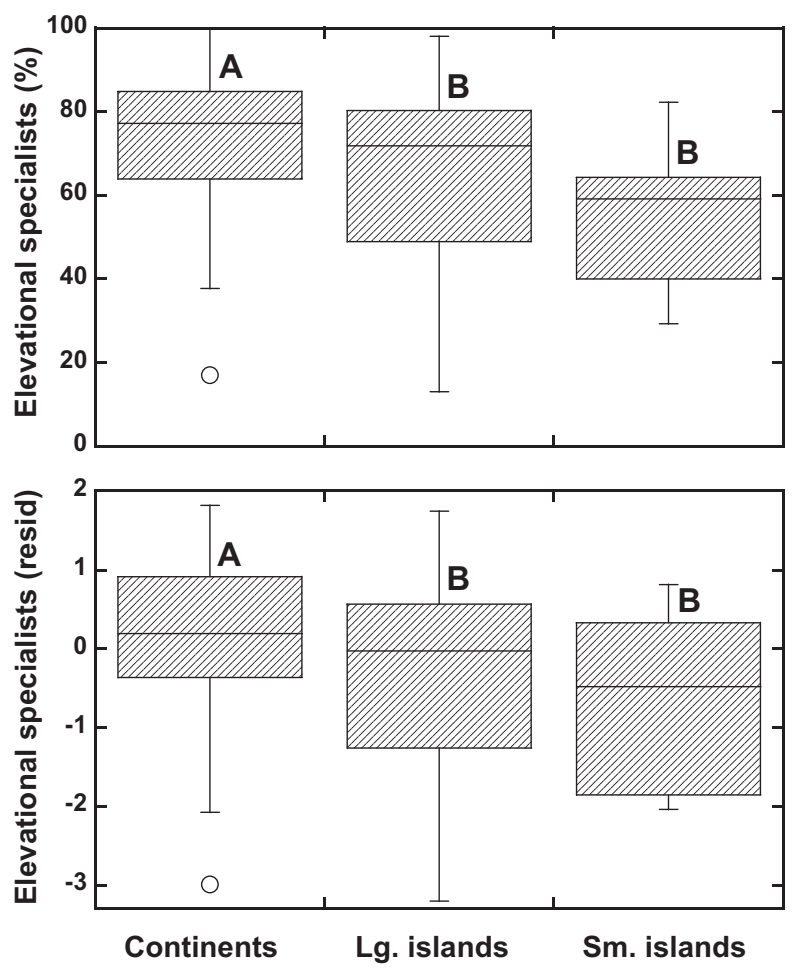

Fig. 4. Box-plot comparisons of the incidence of elevational specialists among tropical continents, large islands, and small islands. Comparisons are based on percentage of specialists in each of 150 different studies (above) and the standardized residuals of these percentages once effects of variation in median elevation and elevational range of the study were removed statistically (below). Different letters denote significant differences.

whereas the total elevational range was higher on continents than on large $(P<0.05)$ and small $(P<0.001)$ islands (Tukey's tests).

\subsection{Comparisons among taxa}

Finally, the GLM analyses (Table 2) revealed that a significantly smaller proportion of endothermic vertebrates were upper-zone specialists, relative to ectothermic vertebrates and plants (Fig. 6). Upper-zone-specialist invertebrates were intermediate in frequency and did not differ significantly from the other taxa $(P>0.10)$. However, there were no significant differences among taxa in the proportions of species that were lower-zone specialists.
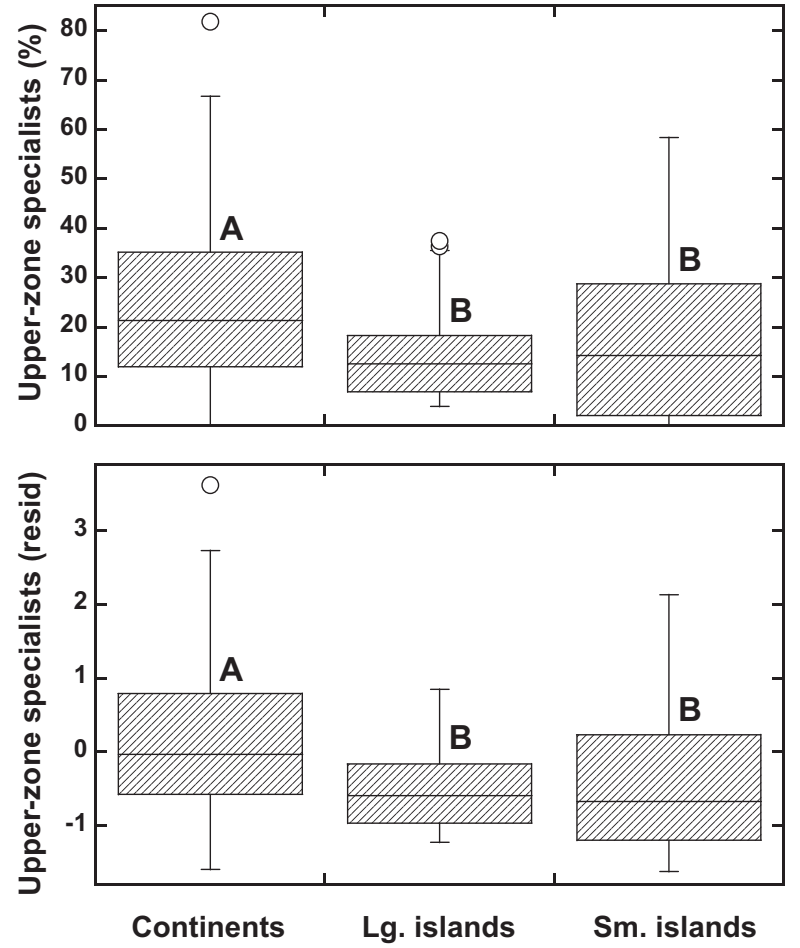

Fig. 5. Box-plot comparisons of the incidence of highland specialists among tropical continents, large islands, and small islands. Comparisons are based on percentage of specialists in each of 150 different studies (above) and the standardized residuals of these percentages once effects of variation in median elevation and elevational range of the study were removed statistically (below). Different letters denote significant differences.

These among-taxon differences were consistent regardless of whether different tropical regions (Table 2 ) or continents versus islands (Table 3 ) were being contrasted.

These patterns suggest that assemblages of upper-zone and lower-zone specialists differ both taxonomically and functionally (Fig. 7). On average, the median elevation used to discriminate lower and upper zones was $1750 \pm 608 \mathrm{~m}$. On this basis consistently high percentages of each taxon (46.2-49.7\%) were classified as lower-zone specialists, whereas the percentages of upper-zone specialists were smaller and more variable among taxa (14.6-29.2\%). Relative to lower-zone specialists, assemblages of upper-zone specialists are dominated by plants and ectothermic vertebrates, with fewer invertebrates and even fewer endothermic vertebrates. 

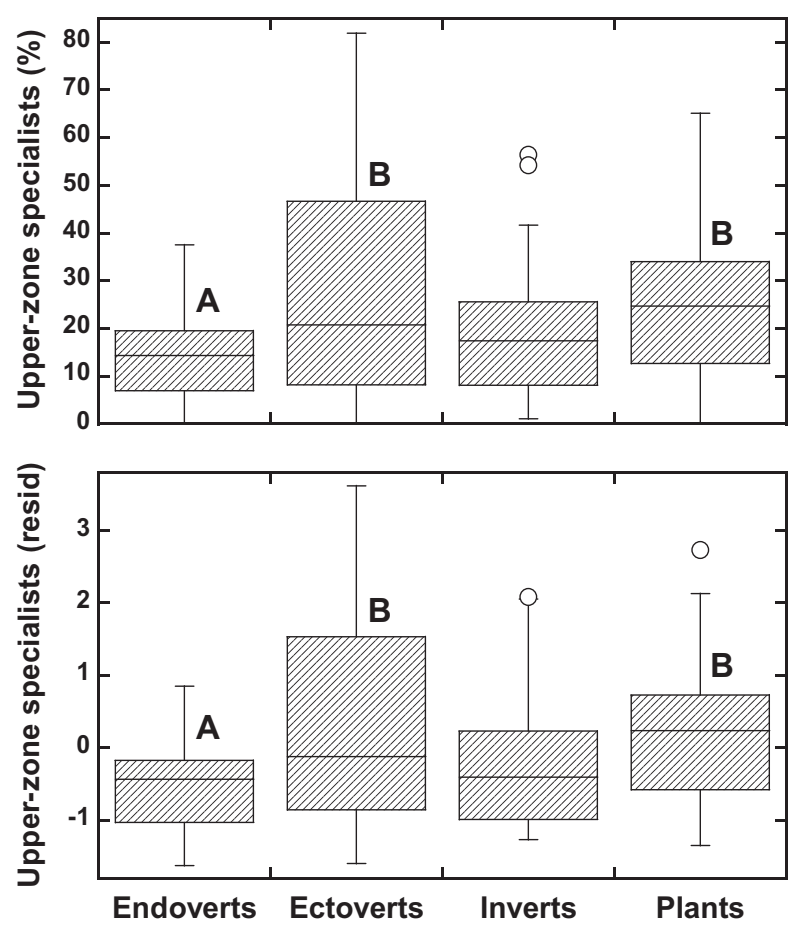

Fig. 6. Box-plot comparisons of the incidence of highland specialists among endothermic vertebrates, ectothermic vertebrates, invertebrates, and plants. Comparisons are based on the percentage of specialists detected in each of 150 different studies (above) and the standardized residuals of these percentages once effects of variation in median elevation and elevational range of the study were removed statistically (below). Different letters denote significantly differing taxa (taxa without letters did not differ significantly from the others).

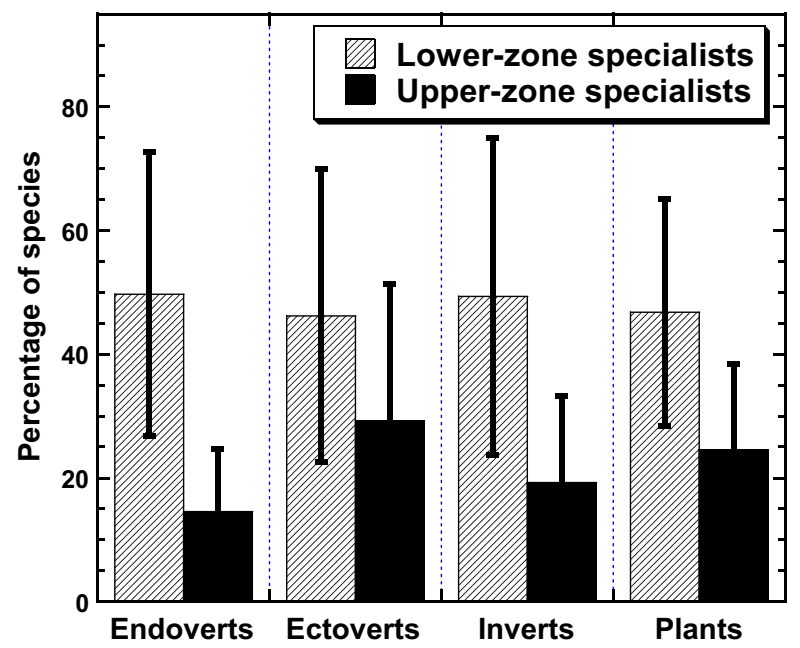

Fig. 7. Mean $( \pm S D)$ percentages of all species classified as lowland and highland specialists, for endothermic vertebrates, ectothermic vertebrates, invertebrates, and plants. Across all 150 datasets, the average elevation used to discriminate lower zone from upper-zone specialists was $1750 \mathrm{~m}$.

Among assemblages of lower-zone specialists, the four groups are all more species rich and more evenly represented (Fig. 7).

\section{Discussion}

\subsection{Comparisons among continents and islands}

Despite the constraints involved in dealing with highly variable datasets, we can draw some key inferences from our study. First, in relative terms the Neotropics appear to be particularly rich in elevational specialists, whereas the Asia-Pacific region seems poorer, with Africa in an intermediate position (Fig. 3). The most plausible explanation, we believe, is that regions with larger, more contiguous, and taller mountain masses are most likely to sustain greater proportions of elevational specialists, especially upper-zone specialists (cf. Bachman et al., 2004; Kattan and Franco, 2004). The Neotropics has the vast Andes, the world's longest mountain range, as well as extensive cordilleras in Central America and the Trans-Mexican Volcanic Belt. Montane regions in Africa and the Asia-Pacific are generally smaller and more scattered, with some notable exceptions such as the highlands of New Guinea and Borneo. With their long thermal gradients, tall mountains provide numerous opportunities for thermal and elevational specialization. Such specialists should also be favored by extinction-colonization dynamics (MacArthur and Wilson, 1967; Thomas, 1994) on large contiguous mountain masses; for instance, large mountain ranges should permit elevational specialists to migrate upward or downward in times of climatic change, maintaining viable population sizes. Further, in the Americas, unlike other continents, the main mountain ranges extend North-South, making it easier for elevational specialists to migrate polewards or equatorwards in response to climatic change.

Second, we found that oceanic and smaller continental islands have relatively fewer elevational specialists (Fig. 4)-especially upper-zone specialists (Fig. 5)-than do the major continents. Large continental islands, such as Borneo and Madagascar, lie somewhere between these two extremes. Again, the most compelling explanation focuses on the height, size, and contiguousness of mountain ranges. This is reflected in the fact that both the median elevation and elevational range of study transects declined progressively from continents to large continental islands to small islands (Table 1). In addition to supporting smaller mountains with lower elevational diversity, islands generally have fewer species, fewer ecological specialists, and species with broader realized niches (because of reduced interspecific competition) than do continents (MacArthur and Wilson, 1967; MacArthur et al., 1972)-all factors that could contribute to a reduced incidence of elevational specialists on islands.

Clearly, factors other than mountain-range height, extent, and contiguousness could also be important in determining the proportions of elevational specialists. Historical stability of the regional climate could be particularly significant (Williams and Pearson, 1997; Fjeldså et al., 1999; Graham et al., 2006; Hemp et al., 2009). During the Pleistocene, for example, tropical rainforests in northeastern Australia repeatedly contracted into a series of small upland refugia, the distribution of which strongly influences current-day patterns of species diversity and elevational specialization (Winter, 1988; Schneider et al., 1998). Today, most rainforest-endemic vertebrates in this region are upland or montane specialists, with the highest diversities found in what were evidently the largest and least irregularly-shaped refugia (Williams and Pearson, 1997). Similarly, in the Andes, hotspots of avian endemism are believed to coincide with cloudy, hyper-wet areas that have been climatically stable for long periods of time (Fjeldså et al., 1999). In addition, geologically young islands or mountain ranges would likely sustain few elevational specialists, because they would not have existed long enough to allow such specialists to evolve in situ (e.g. Ricklefs and Cox, 1972; Frey et al., 2007).

\subsection{Upper-zone versus lower-zone specialists}

Regardless of the taxonomic group involved, we found that upper-zone specialists were consistently less species rich than lower-zone specialists (Fig. 7). This pattern could be influenced by our study design, which involved dividing each study area into 
upper and lower zones at its median elevation. Under this design, mid-elevation specialists whose distributions spanned the median elevation would be classified as elevational generalists. Subdividing elevations more finely was not possible given the enormous variability in sampling design and elevational range among the 150 studies in our analysis. Fortunately, while our design did not permit mid-elevation specialists to be distinguished, it should not have biased our comparisons among different geographic regions or taxa.

In addition, it has been hypothesized that the elevational ranges of species are greatest at higher altitudes-a phenomenon termed the Rapoport Effect (Stevens, 1992). If so then montane species could more often overlap the median elevation than do lowland species, leading them to be classified as elevational generalists more frequently. The Rapoport Effect has some support. Among vertebrates on tropical mountains, elevational-range amplitudes do tend to increase with increasing elevation (McCain, 2009). Among tropical plants, however, elevational ranges tend to be greatest at the middle of elevational gradients, declining towards both ends (Kessler, 2002; Kluge et al., 2008).

Hence, caution is needed when directly comparing the proportions of upper-zone and lower-zone specialists in our study (Fig. 7). Species confined to higher elevations might well be more diverse, in relative terms, than suggested by our analysis.

\subsection{Differences among taxa}

We found no significant differences among four taxonomicfunctional groups-plants, invertebrates, ectothermic vertebrates, endothermic vertebrates-in the proportions of species that were considered lower-zone specialists. However, these groups differed markedly in the proportions of species that were upper-zone specialists (Fig. 6). Relatively fewer endothermic vertebrates were upper-zone specialists compared to ectothermic vertebrates and plants, whereas invertebrates were intermediate in frequency as upper-zone specialists. Thus, in broad terms, our analysis suggests that tropical montane regions are relatively rich in upper-zonespecialist plant, amphibian, and reptile species, moderately rich in upper-zone-specialist invertebrates, and relatively depauperate in upper-zone-specialist bird and mammal species.

Why are relatively few birds and mammals upper-zone specialists? One plausible idea is that endotherms typically have wider climatic tolerances than do ectotherms (Porter and Gates, 1969) and might therefore exhibit less elevational specialization. If so, however, then one would also expect to see relatively few lowerzone-specialist endotherms, a pattern we did not detect (Fig. 7). An alternative (and not mutually exclusive) explanation is that endotherms have far greater energy requirements than do similarly sized ectotherms. An insectivorous songbird, for example, requires $\sim 30$ times as much energy as does an insectivorous lizard of equal body mass (Pough, 1980). Such high energy requirements translate into large area requirements for population persistence. Given past fluctuations in global temperatures, such as the relatively warm interglacial periods of the Pleistocene (Hansen et al., 2006), populations of upper-zone-specialist endotherms would likely have experienced more severe population and range declines, and thus more frequent extinctions, than would species with lower energetic and area requirements.

This view of high endotherm vulnerability is consistent with the finding that species at higher trophic levels, which have greater area requirements, are more sensitive to climatic change than are those at lower trophic levels (Voigt et al., 2003). It is also consistent with the fact that a disproportionately high number of montaneendemic mammal and bird species in the tropics are currently threatened with extinction (Renjifo et al., 1997; Brooks et al., 1999). These species seem exceptionally vulnerable to habitat disruption because their geographic ranges and population sizes are already so small (Brooks et al., 1999). Given the prospects for significant future warming in the tropics (Williams et al., 2003; Colwell et al., 2008), upper-zone-specialist birds and mammals might be most immediately vulnerable. In this sense, the nearextinction in tropical Australia of a highland-endemic possum species, the white lemuroid ringtail (Hemibelideus lemuroides), in response to strong heat wave in late 2005 , might be a harbinger of events to come (Laurance, 2009).

Yet if global warming should continue unabated, the prospects of numerous extinctions of other highland taxa, such as herpetofauna, plants, and invertebrates, will almost certainly increase (Raxworthy et al., 2008; Wake and Vredenburg, 2008), despite their more-limited spatial requirements. High proportions of these taxa are montane specialists (Fig. 6) and many likely have limited vagility and capacity to migrate elsewhere. Thus, the potential for large-scale species losses seems great.

\subsection{Challenges and limitations}

It is important to highlight some limitations of our analysis. First, we evaluated only the frequency of elevational specialistspercentages rather than absolute numbers-a constraint imposed by our analytical strategy. Second, any inferences we make about the relative numbers of upper-zone versus lower-zone specialists is partly an artifact of the median elevation used to distinguish these two groups. Median elevation varied markedly among the 150 studies, averaging $1750 \pm 608 \mathrm{~m}$. As would be expected, studies with higher median elevations tended to identify somewhat higher percentages of lower-zone specialists, simply because the definition of 'lower-zone specialist' was broadened to include more mid-elevation species. In our GLM analyses we treated the median elevation and elevational range of each study as covariates, in an effort to minimize their effects statistically.

Third, our GLM analyses (Tables 2 and 3) had only modest predictive power, explaining $12-19 \%$ of the total variability in our datasets. This is not surprising given the eclectic nature of the 150 studies in our final analysis, which varied greatly in focal taxa, study area, elevational range, and sampling design. At least some of the unexplained variation in our study resulted from inequalities in the relative frequency of different taxa on different continents (Fig. 1).

Fourth, a problem in any field study is that of false absences, in which a species is presumed to be absent from an area when in fact it is present but simply not detected (MacKenzie et al., 2003; Ferraz et al., 2007). Clearly, the studies we evaluated suffered from this limitation, meaning that some species perceived to be elevational specialists were in fact more generalized than indicated here. This problem, however, is less vexing than one might suppose. Our study was specifically designed to minimize systematic bias caused by false absences, by equalizing sampling effort in the upper and lower elevational zones. In addition, a particular species is most likely to be missed in field studies where it is rare. Such areas are usually marginal habitat for the species, and thus less crucial for its long-term persistence, than are the core areas of its elevational range (Williams et al., 2009), where it is most likely to be detected.

Lastly, our analyses focused on patterns of elevational specialization, rather than thermal specialization per se. A species might be confined to a particular elevational range because it is a habitat specialist, rather than a thermal specialist (e.g. Richardson et al., 2005), or even because its elevational range is limited by interspecific competition (Price and Kirkpatrick, 2009; Jankowski et al., 2010). Many habitat features co-vary with elevation; for instance, vegetation architecture tends to become denser and more stunted at higher elevations until above the treeline, where it is far simpler 
in structure (Heaney, 2001). In many cases, we suspect, species are responding both to temperature and other habitat cues in selecting their elevational range and microhabitats (Huey and Webster, 1976; Hertz, 1979; Hodkinson, 2005).

\section{Conclusions}

Our analysis provides a broad perspective on the influence of geographic factors and taxonomic-functional groups on patterns of elevational specialization in tropical animals and plants. Elevational specialists-especially upper-zone specialists-are evidently most frequent in the Americas, which have the largest and most contiguous mountain ranges of any continent; and they are least frequent on oceanic and smaller continental islands.

In terms of their assemblage composition, upper-zone specialists are distinctive from lower-zone specialists. They comprise a smaller proportion of all species than do lower-zone specialists, but as a group they are probably more extinction prone given their vastly smaller geographic ranges. Despite likely having experienced prior extinction-filters (Balmford, 1996) during earlier warm periods, highland-specialist birds and mammals might be particularly vulnerable to global warming because of their small geographic ranges and high energetic and area requirements. Ectotherms and plants are often more species rich than birds and mammals in montane regions and could also become vulnerable if global warming continues unabated.

Our comparative approach has some obvious limitations but clearly complements more detailed, local investigations of species responses to climatic change. Among the highest priorities for such local studies are documenting the rates of ongoing elevational shifts in montane species (Raxworthy et al., 2008; Sekercioglu et al., 2008; Chen et al., 2009). Another key priority is identifying the upper thermal limits and acclimation capacity of a representative suite of tropical species, and the physiological, genetic, and behavioral traits that influence thermal tolerance (Deutsch et al., 2008; Williams et al., 2008).

It is vital to emphasize that in coming decades, biota in tropical regions will be affected by far more than rising temperatures per se. Realistic scenarios of future warming suggest that the cloud base of tropical mountains, which provides crucial inputs of moisture from cloud-stripping while limiting forest desiccation via shading, could shift hundreds of meters upward in the dry season (Still et al., 1999). As tropical temperatures rise, substantial shifts in regional precipitation are possible (Vera et al., 2006). Higher temperatures could expose montane biota to an array of new pathogens, competitors, and predators that migrate to higher elevations (Pounds et al., 2006; Laurance, 2008; Wright et al., 2009). Finally, further habitat loss and fragmentation and rising hunting pressure will exacerbate the effects of rising temperature for many species (Laurance and Peres, 2006; Thuiller et al., 2006). Global warming is a serious and growing threat, but its potentially far-reaching synergisms with other environmental perils are even more alarming.

\section{Acknowledgements}

D. Bickford, R.K. Colwell, R. Condit, S.J. Wright, and two anonymous referees offered many useful comments and discussion. We thank the many investigators who provided insights or access to unpublished data, especially R. Gradstein, H. Kürschner, T. Nakashizuka, and the Missouri Botanical Garden and TEAM initiative. The Smithsonian Tropical Research Institute, James Cook University, and Australian Research Council provided support. Appendices listing the studies used in this analysis, and describing the study area and sampling methods for each, are available from the lead author upon request.

\section{References}

Addo-Bediako, A.S., Chown, S., Gaston, K.J., 2000. Thermal tolerance, climatic variability and latitude. Proceedings of the Royal Society of London B 267, 739-745.

Bachman, S., Baker, W.J., Brummitt, N., Dransfield, J., Moat, J., 2004. Elevational gradients, area and tropical island diversity: an example from the palms of $\mathrm{New}$ Guinea. Ecography 27, 299-310.

Balmford, A., 1996. Extinction filters and current resilience: the significance of past selection pressures for conservation biology. Trends in Ecology and Evolution 11, 193-196.

Brooks, T.M., Pimm, S.L., Kapos, V., Ravilious, C., 1999. Threat from deforestation to montane and lowland birds and mammals in insular South-East Asia. Journal of Animal Ecology 68, 1061-1078.

Chen, I.-C., Shiu, H.-J., Benedick, S., Holloway, J., Chey, V., Barlow, H., Hill, J., Thomas C.D., 2009. Elevation increases in moth assemblages over 42 years on a tropical mountain. Proceedings of the National Academy of Sciences United States of America 106, 1479-1483.

Clark, D.A., Piper, S., Keeling, C., Clark, D.B., 2003. Tropical rain forest tree growth and atmospheric carbon dynamics linked to interannual temperature variation during 1984-2000. Proceedings of the National Academy of Sciences United States of America 100, 5852-5857.

Cochrane, M.A., 2003. Fire science for rainforests. Nature 421, 913-919.

Colwell, R.K., Brehm, G., Cardelus, C., Gilman, A., Longino, J., 2008. Global warming, elevational range shifts, and lowland biotic attrition in the wet tropics. Science $322,258-261$.

Deutsch, C.A., Tewksbury, J., Huey, R.B., Sheldon, K., Ghalambor, C., Haak, D., Martin, P.R., 2008. Impacts of climate warming on terrestrial ectotherms across latitude. Proceedings of the National Academy of Sciences United States of America 105 6668-6672.

Dillon, M.E., Wang, G., Huey, R.B., 2010. Global metabolic impacts of recent climate warming. Nature 467, 704-707.

Feeley, K.J., Wright, S.J., Supardi, M., Kassim, A., Davies, S., 2007. Decelerating growth in tropical forest trees. Ecology Letters 10, 461-469.

Ferraz, G., Nichols, J.D., Hines, J., Stouffer, P., Bierregaard, R., Lovejoy, T.E., 2007. A large-scale deforestation experiment: effects of patch area and isolation on Amazon birds. Science 315, 238-241.

Fjeldså, J., Lambin, E., Mertens, B., 1999. Correlation between endemism and local ecoclimatic stability documented by comparing Andean bird distributions and remotely sensed land surface data. Ecography 22, 63-78.

Fjeldså, J., Lovett, J., 1997. Geographical patterns of old and young species in African forest biota: the significance of specific montane areas as evolutionary centres. Biodiversity and Conservation 6, 325-346.

Frey, J., Bogan, M., Yates, T., 2007. Mountaintop island age determines species richness of boreal mammals in the American Southwest. Ecography 30, 231-240.

Ghalambor, C.K., Huey, R.B., Martin, P., Tewksbury, J., Wang, G., 2006. Are mountain passes higher in the tropics? Janzen's hypothesis revisited. Integrative and Comparative Biology 46, 5-17.

Graham, C., Moritz, C., Williams, S.E., 2006. Habitat history improves prediction of biodiversity in a rainforest fauna. Proceedings of the National Academy of Sciences United States of America 103, 632-636.

Hansen, J., Santo, M., Ruedy, R., Lo, K., Lea, D., Medina-Elizade, M., 2006. Global temperature change. Proceedings of the National Academy of Sciences United States of America 103, 14288-14293.

Heaney, L.R., 2001. Small mammal diversity along elevational gradients in the Philippines: an assessment of patterns and hypotheses. Global Ecology and Biogeography 10, 15-39.

Hemp, A., Beck, E., 2001. Erica excelsa as a fire-tolerating component of Mt Kilimanjaro's forests. Phytocoenology 31, 449-475.

Hemp, C., Hemp, A., Wägele, J., 2009. Biogeography, coenology, habitat and morphology of the East African genus Parasphena Bolivar 1884 (Orthoptera: Pyrgomorphidae) and the description of a new species from north-western Tanzania. Journal of Orthoptera Research 18, 113-119.

Hertz, P., 1979. Sensitivity to high temperatures in three West Indian grass anoles, with a review of heat sensitivity in the genus Anolis. Comparative Biochemistry and Physiology 63A, 217-222.

Hilbert, D.W., Bradford, M., Parker, T., Westcott, D., 2004. Golden bowerbird (Prionodura newtoniana) habitat in past, present and future climates: predicted extinction of a vertebrate in tropical highlands due to global warming. Biological Conservation 116, 367-377.

Hodkinson, I.D., 2005. Terrestrial insects along elevation gradients: species and community responses to altitude. Biological Reviews 80, 489-513.

Houghton, J., Ding, Y., Griggs, D., Noguer, M., van der Linden, P., Xiaosu, D. (Eds.), Climate Change 2001: The Scientific Basis. Cambridge University Press, Cambridge, UK.

Huey, R.B., 1976. Latitudinal pattern of between-altitude faunal similarity: mountains might be "higher" in the tropics. American Naturalist 112, 225-254.

Huey, R.B., Deutsch, C., Tewksbury, J., Vitt, L., Hertz, P., Álvarez, H., 2009. Why tropical forest lizards are vulnerable to climate warming. Proceedings of the Royal Society of London B 276, 1939-1948.

Huey, R.B., Webster, T.P., 1976. Thermal biology of Anolis lizards in a complex fauna Cristatellus group on Puerto Rico. Ecology 57, 985-994.

IPCC, 2007. Intergovernmental Panel on Climate Change: Special Report on Emissions Scenarios. <http://www.grida.no/climate/ipcc/emission/098.htm>. 
Jankowski, J.E., Robinson, S.K., Levey, D.J., 2010. Squeezed at the top: interspecific aggression may constrain elevational ranges in tropical birds. Ecology 91, 18771884.

Janzen, D.H., 1967. Why mountain passes are higher in the tropics. American Naturalist 101, 233-249.

Jiguet, F., Julliard, R., Thomas, C.D., Dehorter, O., Newson, S., Couvet, D., 2006. Thermal range predicts bird population resilience to extreme high temperatures. Ecology Letters 9, 1321-1330.

Kattan, G.H., Franco, P., 2004. Bird diversity along elevational gradients in the Andes of Colombia: area and mass effects. Global Ecology and Biogeography 13, 451458.

Kessler, M., 2002. Range size and its ecological correlates among the pteridophytes of Carrasco National Park, Bolivia. Global Ecology and Biogeography 11, 89-102.

Kluge, J., Bach, K., Kessler, M., 2008. Elevational distribution and zonation of tropical pteridophyte assemblages in Costa Rica. Basic and Applied Ecology 9, 35-43.

Krockenberger, A., Kitching, R., Turton S., 2004. Environmental Crisis: Climate Change and Terrestrial Biodiversity in Queensland. CRC for Tropical Rainforest Ecology and Management, Cairns, Australia.

Laurance, W.F., 2004. Forest-climate interactions in fragmented tropical landscapes. Philosophical Transactions of the Royal Society of London B 359, 345-352.

Laurance, W.F., 2008. Global warming and amphibian declines in eastern Australia. Austral Ecology 33, 1-9.

Laurance, W.F., 2009. Move Over, Polar Bear. New Scientist 10 November, p. 14

Laurance, W.F., Oliveira, A.A., Laurance, S.G., Condit, R., Nascimento, H. Sanchez-Thorin, A., Lovejoy, T., Andrade, A., D’Angelo, S., Dick, C., 2004 Pervasive alteration of tree communities in undisturbed Amazonian forests. Nature 428, 171-175.

Laurance, W.F., Peres, C.A. (Eds.), 2006. Emerging Threats to Tropical Forests. University of Chicago Press, Chicago.

Lewis, S.L., Lopez-Gonzalez, G., Sonke, B., Affum-Baffoe, K., Baker, T.R., Ojo, L.O., Phillips, O.L., Reitsma, J.M., White, L., Comiskey, J.A., Djuikouo, K.M., Ewango, C.E., Feldpausch, T.R., Hamilton, A.C., Gloor, M., Hart, T., Hladik, A., Lloyd, J., Lovett, J.C., Makana, J.R., Malhi, Y., Mbago, F.M., Ndangalasi, H.J., Peacock, J., Peh, K.S., Sheil, D., Sunderland, T., Swaine, M.D., Taplin, J., Taylor, D., Thomas, S.C., Votere, R., Woll, R., 2009. Increasing carbon storage in intact African tropical forests. Nature 457, 1003-1006.

MacArthur, R.H., Diamond, J.M., Karr, J., 1972. Density compensation in island faunas. Ecology 53, 330-342.

MacArthur, R.H., Wilson, E.O., 1967. The Theory of Island Biogeography. Princeton University Press, Princeton, New Jersey.

MacKenzie, D., Nichols, J.D., Hines, J., Knutson, M., Franklin, A., 2003. Estimating site occupancy, colonization, and local extinction when a species is detected imperfectly. Ecology 84, 2200-2207.

McCain, C.M., 2004. The mid-domain effect applied to elevational gradients: species richness of small mammals in Costa Rica. Journal of Biogeography 31, 19-31.

McCain, C.M., 2009. Vertebrate range sizes indicate that mountains may be 'higher' in the tropics. Ecology Letters 12, 550-560.

Pearson, R.G., Dawson, T.P., 2005. Long-distance plant dispersal and habitat fragmentation: identifying conservation targets for spatial landscape planning under climate change. Biological Conservation 123, 389-401.

Peters, R.L., Lovejoy, T.E. (Eds.), 1994. Global Warming and Biological Diversity. Yale University Press, New Haven, Connecticut.

Phillips, O.L., Malhi, Y., Higuchi, N., Laurance, W.F., Nuñez, P.V., Vasquez, R.M. Laurance, S.G., Ferreira, L.V., Stern, M., Brown, S., Grace, J., 1998. Changes in the carbon balance of tropical forests: evidence from long-term plots. Science 282 439-442.

Porter, W.P., Gates, D., 1969. Thermodynamic equilibria of animals with environment. Ecological Monographs 39, 227-244.

Pough, F.H., 1980. The advantages of ectothermy for tetrapods. American Naturalist $115,92-112$

Pounds, J.A., Bustamente, M., Coloma, L., Consuegra, J., Fogden, M., Foster, P., La Marca, E., Masters, K., Merino-Viteri, A., Puschendorf, R., Ron, S. Sanchez-Azofeifa, A., Still, C., Young, B., 2006. Widespread amphibian extinctions from epidemic disease driven by global warming. Nature 439, 161-167.

Pounds, J.A., Fogden, M., Campbell, J., 1999. Biological response to climate change on a tropical mountain. Nature 398, 611-615.

Price, T.D., Kirkpatrick, M., 2009. Evolutionarily stable range limits set by interspecific competition. Proceedings of the Royal Society of London B 276, 1429-1434.

Rahbek, C., 1997. The relationship among area, elevation, and regional species richness in Neotropical birds. American Naturalist 149, 875-902.

Raxworthy, C.J., Pearson, R.G., Rabibisoa, N., Rakotondrazafy, A., Ramanamanjato, J., Raselimanana, A., Wu, S., Nussbaum, R., Stone, D., 2008. Extinction vulnerability of tropical montane endemism from warming and upslope displacement: a preliminary appraisal for the highest massif in Madagascar. Global Change Biology 14, 1703-1720.

Renjifo, L.M., Servat, G., Goerck, J., Loiselle, B., Blake, J., 1997. Patterns of species composition and endemism in the northern Neotropics: a case for conservation of montane avifaunas. Ornithological Monographs 48, 577-594.

Richardson, B.A., Richardson, M., Soto-Adames, A., 2005. Separating the effects of forest type and elevation on the diversity of litter invertebrate communities in a humid tropical forest in Puerto Rico. Journal of Animal Ecology 74, 926-936.

Ricketts, T.H., Dinerstein, E., Boucher, T., Brooks, T.M., Butchart, S.H., Hoffmann, M., Lamoreux, J.F., Morrison, J., Parr, M., Pilgrim, J.D., Rodrigues, A.S., Sechrest, W., Wallace, G.E., Berlin, K., Bielby, J., Burgess, N.D., Church, D.R., Cox, N., Knox, D. Loucks, C., Luck, G.W., Master, L.L., Moore, R., Naidoo, R., Ridgely, R., Schatz, G.E. Shire, G., Strand, H., Wettengel, W., Wikramanayake, E., 2005. Pinpointing and preventing imminent extinctions. Proceedings of the National Academy of Sciences United States of America 102, 18497-18501.

Ricklefs, R.E., Cox, G.C., 1972. Taxon cycles in the West Indian avifauna. American Naturalist 106, 195-219.

Schneider, C.J., Cunningham, M., Moritz, C., 1998. Comparative phylogeography and the history of endemic vertebrates in the wet tropics rain forests of Australia. Molecular Ecology 7, 487-498.

Sekercioglu, C.H., Schneider, S., Fay, J., Loarie, S., 2008. Climate change, elevational range shifts, and bird extinctions. Conservation Biology 22, 140-150.

Stevens, G.C., 1992. The elevational gradient in altitudinal range: an extension of Rapoport's latitudinal rule to altitude. American Naturalist 140, 893-911.

Still, C.J., Foster, P., Schneider, S., 1999. Simulating the effects of climate change on tropical montane cloud forests. Nature 398, 608-610.

Terborgh, J., 1977. Bird species diversity on an Andean elevational gradient. Ecology 58, 1007-1019.

Tewksbury, J.J., Huey, R.B., Deutsch, C., 2008. Putting the heat on tropical animals. Science 320, 1296-1297.

Thomas, C.D., 1994. Extinction, colonization and metapopulations: environmental tracking by rare species. Conservation Biology 8, 373-378.

Thomas, C.D., Cameron, A., Green, R.E., Bakkenes, M., Beaumont, L.J., Collingham, Y.C., Erasmus, B.F., De Siqueira, M.F., Grainger, A., Hannah, L., Hughes, L., Huntley, B., Van Jaarsveld, A.S., Midgley, G.F., Miles, L., Ortega-Huerta, M.A. Peterson, A.T., Phillips, O.L., Williams, S.E., 2004. Extinction risk from climate change. Nature 427, 145-148.

Thuiller, W., Broennimann, O., Hughes, G., Akemades, J., Midgley, G., Corsi, F., 2006. Vulnerability of African mammals to anthropogenic climate change under conservative land transformation assumptions. Global Change Biology 12, 424-440.

van Berkum, F.H., 1988. Latitudinal patterns of the thermal sensitivity of sprint speed in lizards. American Naturalist 132, 327-343.

Vera, C., Silvestri, G., Liebmann, B., Gonzalez, P., 2006. Climate change scenarios for seasonal precipitation in South America from IPCC-AR4 models. Geophysical Research Letters 33, L13707. doi:10.1029/2006GL025759.

Voigt, W. et al., 2003. Trophic levels are differentially sensitive to climate. Ecology 84, 2444-2453.

Wake, D.B., Vredenburg, V.T., 2008. Are we in the midst of the sixth mass extinction? A view from the world of amphibians. Proceedings of the National Academy of Sciences United States of America 105, 11466-11473.

Weathers, W.W., 1997. Energetics and thermoregulation by small passerines of the humid, lowland tropics. Auk 113, 341-353.

Williams, J.W., Jackson, S., Kutzbach, J., 2007. Projected distributions of novel and disappearing climates by 2100 AD. Proceedings of the National Academy of Sciences United States of America 104, 5738-5742.

Williams, S.E., Bolitho, E., Fox, S., 2003. Climate change in Australian tropical rainforests: an impending environmental catastrophe. Proceedings of the Royal Society of London B 270, 1887-1892.

Williams, S.E., Pearson, R.G., 1997. Historical rainforest contractions, localized extinctions and patterns of vertebrate endemism in the rainforests of Australia's wet tropics. Proceedings of the Royal Society of London B 264, 709-716.

Williams, S.E., Shoo, L.P., Henriod, R., Pearson, R.G., 2009. Elevational gradients in assemblage structure and productivity for rainforest birds in the Australian wet tropics bioregion. Austral Ecology, doi:0.1111/j.1442-9993.2009.02073.x.

Williams, S.E., Shoo, L.P., Isaac, J., Hoffman, A., Langham, G., 2008. Towards an integrated framework for assessing the vulnerability of species to climate change. PLoS Biology 6, e325. doi:10.1371/journal.pbio.0060325.

Winter, J.W., 1988. Ecological specialization of mammals in Australian tropical and subtropical rain forest: refugial or ecological determinism? Proceedings of the Ecological Society of Australia 15, 127-138.

Wright, S.J., Muller-Landau, H., Schipper, J., 2009. The future of tropical species on a warmer planet. Conservation Biology 6, 1418-1426. 